\title{
Urgences
}

\section{La moindre boucherie}

\section{Michel Gay}

Numéro 19, janvier 1988

Le tour du texte

URI : https://id.erudit.org/iderudit/025450ar

DOI : https://doi.org/10.7202/025450ar

Aller au sommaire du numéro

Éditeur(s)

Urgences

ISSN

0226-9554 (imprimé)

1927-3924 (numérique)

Découvrir la revue

Citer ce document

Gay, M. (1988). La moindre boucherie. Urgences, (19), 87-93.

https://doi.org/10.7202/025450ar

Ce document est protégé par la loi sur le droit d'auteur. L'utilisation des services d'Érudit (y compris la reproduction) est assujettie à sa politique d'utilisation que vous pouvez consulter en ligne.

https://apropos.erudit.org/fr/usagers/politique-dutilisation/
Cet article est diffusé et préservé par Érudit.

Érudit est un consortium interuniversitaire sans but lucratif composé de l’Université de Montréal, l'Université Laval et l'Université du Québec à Montréal. Il a pour mission la promotion et la valorisation de la recherche. https://www.erudit.org/fr/ 


\section{Michel Gay \\ LA MOINDRE BOUCHERIE}




$$
t_{7}
$$



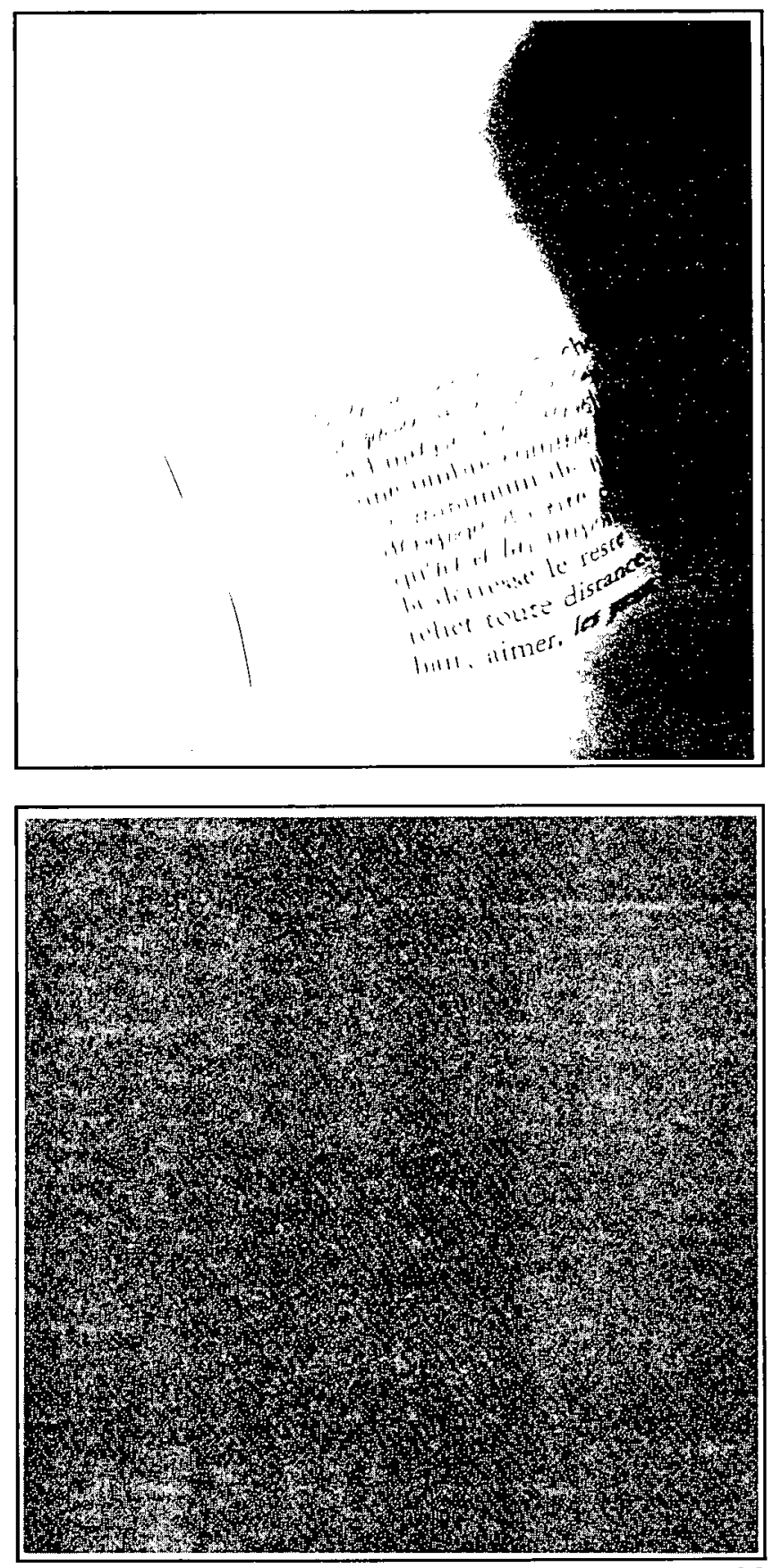
I'appelle danc sitot la moindre boncherie hypentexte tout texte décivé diun texte antéreur [* hupptexte; lo geote unetjoill] par tranoporuction simple (nous dirms de'sormais tranoprimation put colunt) bu pan traing oviniation indikete des indices: a I'untésien du tondier nous divons une ombre initation : [.]

E.] Thypentox realite os une pratique tranogenevique qui comprend conume in minimum de vécessité quelque genres ditskmineuns $\gg$ conme a parodie, dérajage de rive dow ce qui nuavilue quici et lá le traveotissement - inupossible de détounver a détresse: le paotiche le digast etc, et qui traverse 6 reste, relief toute distance, tous los antres.

[..] ihypentatualike oot evidemment [. ] un des traits par boguels ine centaina moker nité on postrodernité

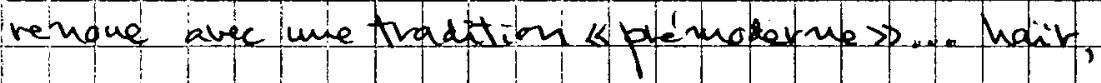
aimer, lds yeux pen wéd. 


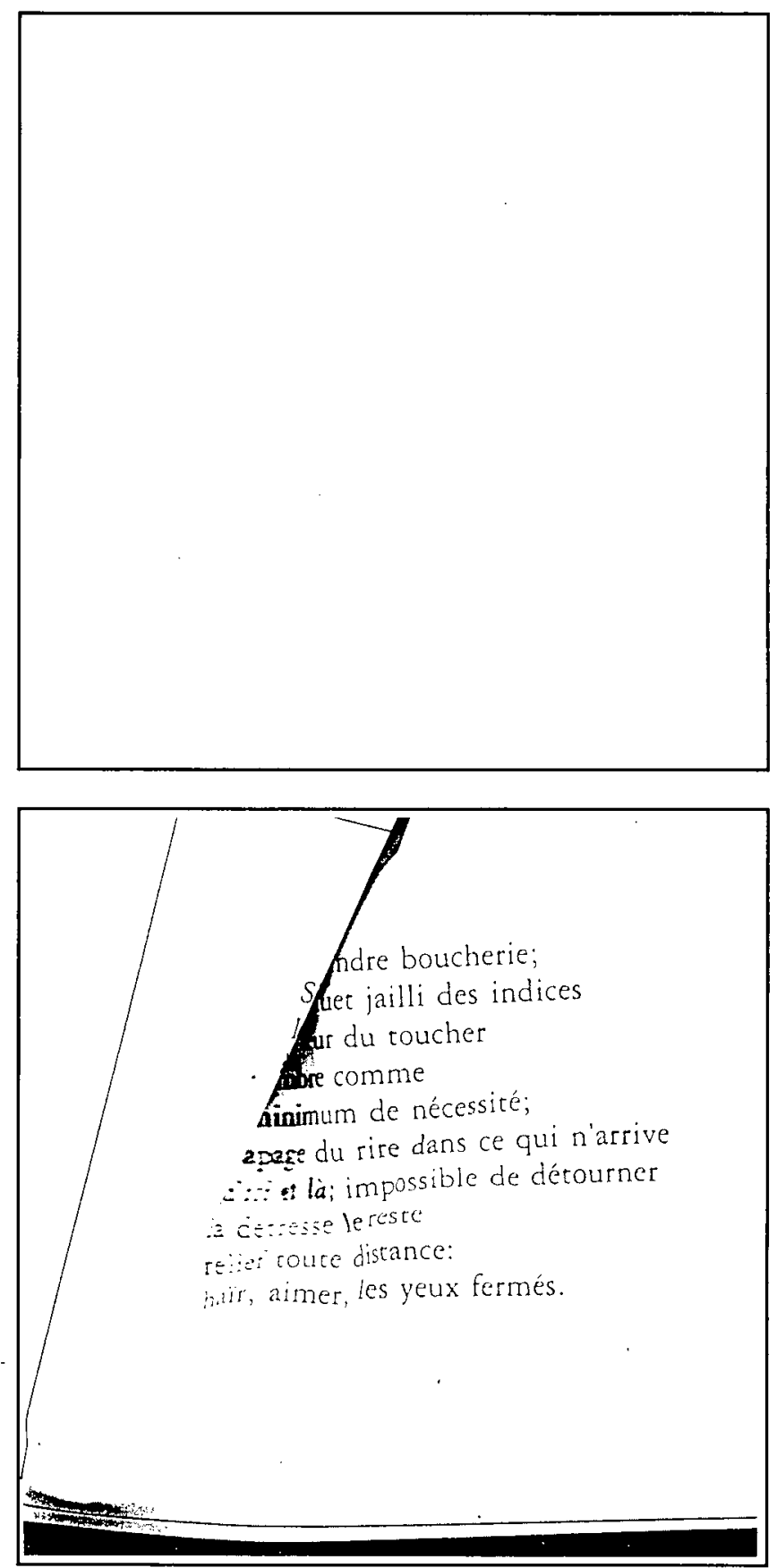
à gérard genette quebec, 1987

93 